\title{
Comparison of Regional Blood Flow Values Measured by Radioactive and Fluorescent Microspheres
}

\author{
E. Thein S. Raab A.G. Harris M. Kleen O. Habler F. Meisner \\ K. Messmer \\ Institute for Surgical Research, University of Munich, Germany
}

\section{Key Words}

Microspheres · Sample processing · Regional organ blood flow
$16.5 \%)$ of both methods. Our results indicate the validity of MS and of the automated tissue processing technique by means of the SPU.

Copyright $@ 2002$ S. Karger AG, Basel

\begin{abstract}
Fluorescent microspheres (FM) have become an attractive alternative to radioactive microspheres (RM) for the measurement of regional blood flow (RBF). The aim of the present study was to investigate the comparability of both methods by measuring RBF with FM and RM. Eight anaesthetised pigs received simultaneous, left atrial injections of FM and RM with a diameter of $15 \mu \mathrm{m}$ at six different time points. Blood reference samples were collected from the descending aorta. RBF was determined in tissue samples of the myocardium, spleen and kidneys of all 8 animals. After radioactivity of the tissue samples was determined, the samples were processed automatically for measuring fluorescence using a recently developed filter device (SPU). RBF was calculated with both the isotope and spectrometric data of both methods for each sample resulting in a total of 10,512 blood flow values. The comparison of the RBF values yielded high linear correlation (mean $r^{2}=0.95 \pm 0.03$ to $0.97 \pm 0.02$ ) and excellent agreement (bias 5.4-6.7\%, precision 9.9-
\end{abstract}

\section{Introduction}

Fluorescent microspheres (FM) have become an acceptable alternative to radioactive microspheres (RM) in blood flow measurements since they were first introduced by Glenny et al. [1] in 1993. These authors recovered the FM from the tissue samples and the blood references by digestion of the samples in aqueous $\mathrm{KOH}$ followed by the filtration of the digestate through a polycarbonate-membrane. The disadvantage of this recovery procedure is that FM of an unknown amount might be lost when the liquid is transferred from the digestion container onto the filter membrane [1,2].

In 1995, van Oosterhout et al. [3] introduced a novel, simplified method for recovering FM from tissue samples. Here the samples are digested in $1 N$ ethanolic $\mathrm{KOH}$ and the digestate is centrifuged for several times, thus forcing the FM to form a pellet on the bottom of the digestion container. The liquid above the pellet is aspirated

\section{KARGER \\ Fax + 41613061234 E-Mail karger@karger.ch www. karger.com

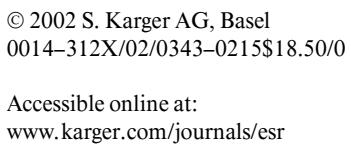

Dr. Eckart Thein

Institute for Surgical Research, Klinikum Grosshadern

Marchioninistrasse 27

D-81366 Munich (Germany)

Tel. +49 897095 4371, Fax +49897095 8897, E-Mail ethein@icf.med.uni-muenchen.de 
and the dyes are dissolved from the FM by adding organic solvent to the pellet. A transfer of the solution is not necessary with this procedure, but FM may be lost while the supernatant is removed [2]. Furthermore, the complete removal of $\mathrm{KOH}$ cannot be assured using this method. This might lead to the loss of fluorescence after the dyes are released from the spheres as they are not stabile at non-neutral $\mathrm{pH}$ values $[2,4]$. In other words, there is a potential for a loss of FM or fluorescence involved in both methods commonly used to recover FM from tissue samples. Therefore, the resulting blood flow values might not be reliable. Another disadvantage of both methods is the long time duration of the digestion period $(24 \mathrm{~h}$ in the filtration and $48 \mathrm{~h}$ in the sedimentation technique).

We have recently developed and validated in vitro a new sample processing unit (SPU) for processing tissue samples from animals having received injections of FM for the measurement of regional blood flow [2]. The advantage of the SPU is that all steps of tissue processing are performed in the identical filter unit through which the digestate is finally filtered. As the samples stay within a single container throughout the whole procedure and aspiration of a supernatant is not necessary, a loss of FM from the tissue and reference samples is excluded [5]. In addition, when using the SPU, the tissue samples can be processed automatically be means of a recently introduced robotic system which highly standardises the whole procedure [4].

The aim of the present study was to determine RBF in samples of the heart, kidney and spleen by means of FM, using the SPU for automated sample processing and to compare the data with blood flow values simultaneously measured by means of RM.

\section{Methods}

\section{Surgical Preparation}

The experiments were approved by the local Bavarian government (Ref.-No.: 211-2531.3-35/96).

Pigs $(n=8)$ of the German Land Breed, weighing from 22 to 45 $\mathrm{kg}$, were anaesthetised with ketamine $\left(10 \mathrm{mg} / \mathrm{kg}\right.$ BW, Ketavet ${ }^{\circledR}$, Pharmacia \& Upjohn GmbH, Erlangen, Germany), Midazolam $(0.3 \mathrm{mg} /$ kg BW, Dormicum ${ }^{\circledR}$, Hoffmann-La Roche, Grenzach-Wyhlen, Germany) and Atropin (0.02-0.05 mg/kg BW, B Braun, Melsungen, Germany). They were intubated and mechanically ventilated (Servo 900 C, Siemens-Selvo, Sweden). The respirator setting was adjusted to maintain normocapnia. Anaesthesia was performed with continuous infusion of Fentanyl (30 ml/h, Fentanyl, Janssen, Neuss, Germany) and Midazolam $(14 \mathrm{ml} / \mathrm{h})$ driven by pumps.

Catheters were placed into the inferior aorta (arterial blood reference) via the right femoral artery, into the right jugular vein (anesthesia and treatment), into the left carotid artery (arterial blood pres- sure) and into the superior caval vein (central venous blood pressure) via the left external jugular vein. Arterial blood pressure was monitored by means of a Millar Microtip Pressure Transducer (Nellcor, Hayward, Calif., USA). To stabilise the circulation and to replace the loss of blood by reference sampling, the animals received physiologic saline solution by infusion throughout the whole experiment. A laparotomy was performed and a catheter was placed into the bladder for the collection of urine. The chest of the animals was opened by a medial incision of the sternum and the pericardium was opened. A flow probe (T208 transonic volume flowmeter, Nellcor) was placed around the aorta for the measurement of cardiac output (CO). The left atrium was fixed with a padded clamp and incised. A catheter for the injection of microspheres was introduced through the incision and the atrium was closed with a circular suture.

\section{Preparation and Injection of Microspheres}

The RM (15 $\mu \mathrm{m}$ in diameter, NEN-Trac, DuPont, Wilmington, Del., USA) used, were labelled with the isotopes ${ }^{141} \mathrm{Ce},{ }^{51} \mathrm{Cr},{ }^{114} \mathrm{In}$, ${ }^{95} \mathrm{Nb},{ }^{46} \mathrm{Sc}$ and ${ }^{185} \mathrm{Sr}$ emitting $\gamma$-radiation. The numbers of spheres of each species were microscopically counted repeatedly in aliquots of the stock solutions and the radioactivity of this known amount of spheres was determined using a $\gamma$-counter (Autogamma 5650, Canberra Packard, Frankfurt am Main, Germany). This enabled us to determine the radioactivity of a single sphere and thus to verify the number of spheres per tissue sample.

The number of spheres in an aliquot of the stock solution of the fluorescent microspheres $(15 \mu \mathrm{m}$ in diameter, Fluospheres, Molecular Probes, Leiden, The Netherlands) was counted using a fluorescent aided cell sorter (FLUVO V, Institute for Surgical Research, Munich, Germany) and the fluorescence intensity of the aliquot was measured. Thus the number of spheres per tissue sample could be calculated from the total fluorescence intensity of each sample. The FM used in the experiments were of the colours blue, blue-green, yellowgreen, orange, red, crimson and scarlet.

Before the injection the radioactive spheres were mixed by vigorously vortexing (Genie 2, Bender \& Hobein AG, Zurich, Switzerland) for $5 \mathrm{~min}$ and $4 \times 10^{6}$ spheres were then transferred into an injection chamber. The chamber was vortexed again.

The glass vials with the FM were vortexed twice for 5 min each time, interrupted by sonication (Sonorex TK52H, Bandelin, Berlin, Germany) for several minutes. $4 \times 10^{6}$ fluorescent microspheres were then drawn off from the vial using a plastic syringe. The spheres were transferred into the injection chamber in which RM and FM were mixed by vortexing for several minutes.

The inlet of the injection chamber was then connected to a plastic syringe ( $\mathrm{vol} 50 \mathrm{ml}$ ) which was filled with saline solution; the outlet of the chamber was connected to the injection catheter. A pump ('33'Syringe Pump, FMI, Egelsbach, Germany) for the collection of an arterial reference blood sample (withdrawal rate $=3.24 \mathrm{ml} / \mathrm{min}$ ) was then started. Arterial blood was sampled for three minutes. At the moment when blood appeared in the reference catheter, the injection of the microspheres was started by pressing the saline solution off the syringe into the chamber. Thereby, the spheres were flushed into the injection catheter. During the injection procedure the chamber was shaken gently to prevent the sedimentation of the spheres and to avoid adherence of the spheres to the walls of the chamber.

The combinations of RM and FM were chosen using a random number generator (Watcom $\mathrm{C} / \mathrm{C}++$ Compiler v.10, Powersoft, Concord, Mass., USA). The number of RM species was limited to 6 different isotopes due to legal restriction. Therefore, each individual 
Table 1. Hemodynamics and blood chemistry

\begin{tabular}{llllllllllll}
\hline $\begin{array}{l}\text { Experiment } \\
\text { No. }\end{array}$ & $\begin{array}{l}\mathrm{BW} \\
\mathrm{kg}\end{array}$ & $\begin{array}{l}\text { Injection } \\
\text { interval } \\
\text { min }\end{array}$ & $\mathrm{HR} / \mathrm{min}$ & $\begin{array}{l}\mathrm{CO} \\
\text { liters }\end{array}$ & $\begin{array}{l}\mathrm{AOPm} \\
\mathrm{mm} \mathrm{Hg}\end{array}$ & $\begin{array}{l}\mathrm{CVP} \\
\mathrm{mm} \mathrm{Hg}\end{array}$ & $\mathrm{ABE}$ & $\begin{array}{l}\mathrm{Hb} \\
\mathrm{g} / \mathrm{dl}\end{array}$ & $\begin{array}{l}\mathrm{Hb}-\mathrm{O}_{2} \\
\%\end{array}$ & $\mathrm{pH}^{2}$ & $\mathrm{FiO}_{2}$ \\
\hline 1 & 45 & $15 \pm 7.0$ & $100 / 107$ & $6.0 / 6.2$ & $121 / 125$ & $15 / 13$ & $3.5 / 1.9$ & $8.8 / 8.2$ & $97.8 / 98.0$ & $7.49 / 7.48$ & $0.51 / 0.51$ \\
2 & 29 & $18.8 \pm 4.8$ & $152 / 156$ & $6.7 / 7.5$ & $136 / 158$ & $6 / 7$ & $-1.7 /-1.5$ & $9.7 / 10.6$ & $98.2 / 97.4$ & $7.36 / 7.35$ & $0.52 / 0.52$ \\
3 & 29 & $15 \pm 4.4$ & $107 / 118$ & $4.2 / 4.3$ & $117 / 103$ & $5 / 5$ & $-0.6 /-2.6$ & $9.1 / 7.5$ & $97.0 / 98.1$ & $7.42 / 7.33$ & $0.48 / 0.47$ \\
4 & 25 & $16 \pm 2.2$ & $91 / 99$ & $2.9 / 2.9$ & $92 / 102$ & $6 / 4$ & $1.5 /-1.3$ & $8.7 / 8.4$ & $98.5 / 98.1$ & $7.43 / 7.40$ & $0.52 / 0.52$ \\
5 & 29.5 & $13.6 \pm 2.9$ & $105 / 107$ & $3.8 / 3.3$ & $118 / 117$ & $6 / 4$ & $0.7 / 0.0$ & $10.1 / 10.2$ & $97.7 / 96.3$ & $7.40 / 7.41$ & $0.51 / 0.51$ \\
6 & 24.5 & $12.6 \pm 1.3$ & $99 / 107$ & $2.2 / 2.8$ & $94 / 130$ & $7 / 8$ & $-1.7 /-4.5$ & $9.2 / 9.2$ & $96.4 / 95.0$ & $7.34 / 7.26$ & $0.53 / 0.53$ \\
7 & 22 & $13.8 \pm 1.8$ & $151 / 114$ & $2.8 / 2.5$ & $107 / 120$ & $4 / 6$ & $-0.8 /-1.0$ & $8.7 / 8.3$ & $89.0 / 94.4$ & $7.30 / 7.40$ & $0.51 / 0.57$ \\
8 & 29 & $13.6 \pm 1.3$ & $113 / 118$ & $4.8 / 4.0$ & $97 / 99$ & $3 / 5$ & $0.7 /-1.1$ & $8.6 / 8.2$ & $97.3 / 95.5$ & $7.41 / 7.42$ & $0.52 / 0.52$ \\
\hline
\end{tabular}

The period of time (injection interval, mean $\pm \mathrm{SD}$ ) which elapsed between two consecutive injections was between 12.6 and 18.8 min. The parameters listed were evaluated prior to each injection of microspheres. The values presented here were recorded before the $1 \mathrm{st}$ and before the 6th injection of microspheres. None of the hemodynamic parameters changed significantly at any time point during the individual experiments, indicating that there was no influence on macrohemodynamic due to the high amount of totally injected microspheres (about 4.8 $\times 10^{7}$ per experiment).

The blood chemistry parameters noted prior to each microsphere injection showed no significant changes during the individual experiments, again indicating that there was no systemic influence due to microsphere injection or reference blood sampling. ABE $=\mathrm{Acid}$ base excess.

animal received a total of 6 simultaneous injections at different time points.

In all 8 experiments, the injections were performed by the same person in order not to influence the basic conditions of the experiments. The injection time lasted between 50 and $60 \mathrm{~s}$. A period of 12-18 min (see table 1) for stabilization was allowed between consecutive injections.

At the end of the experiment the animals were euthanised by an intravenous overdose of Pentobarbital-Na $(20 \mathrm{ml}$, Narcoren, Merial, Halbergmoos, Germany) and the organs of interest were removed. The cadaver was then disposed according to the guidelines for radioactive waste.

\section{Hemodynamic and Blood Chemistry Monitoring}

During the experiments, cardiac output was monitored by means of a flow probe (T208 transonic flow meter, Nellcor) placed around the ascending aorta. Central venous pressure was assessed via the proximal port of a Swan-Ganz catheter (7F, Edwards, Anasco, Puerto Rico) located in the superior caval vein via the jugular vein. Mean, systolic and diastolic arterial blood pressures were registered through a catheter (Millar Microtip Pressure Transducer, Nellcor) located in the descending aorta via a carotid artery.

Furthermore, blood samples were collected from the left carotid artery before each injection and $\mathrm{Hb}, \mathrm{pH}$, acid base excess (ABE) and $\mathrm{Hb}-\mathrm{O}_{2}$ were determined.

\section{Organ Preparation and Dissection}

The connective tissue along the hilus of each spleen was removed and the spleen dissected into 20 samples by cutting the organ transversally into slices of about $2.0 \mathrm{~cm}$ width. Thus, a total of 160 tissue samples of the 8 spleens was obtained.

RBF Measured by Radioactive and

Fluorescent Microspheres
Fatty and connective tissue as well as superficial vessels of the heart were removed and the organ was fixed in formalin for 5 days. The atria were then removed from the organ and were dissected into 4 tissue samples each. The remaining ventricles were sliced into 6 (left ventricle) and 5 (right ventricle and septum) horizontal layers, respectively. The right ventricular portion of each layer was separated from the septum and the left ventricle and underwent dissection into 9 tissue samples. Septum and left ventricle of each slice were dissected into 6 specimens. Each specimen was then divided into a sub-epicardial (epi), a mid-myocardial (myo) and a sub-endocardial (endo) tissue sample (table 2). The hierarchy scheme for the left ventricle served to analyse the endo/epi blood flow ratio. A total of 1,240 myocardial tissue samples, including 272 sub-epicardial and subendocardial left-ventricular specimens respectively were obtained from the 8 experiments. The average weight of the myocardial tissue samples was $0.60 \pm 0.43 \mathrm{~g}$.

The capsule of the kidneys was removed and the organs were sliced horizontally from pole to pole. The connective tissue of the renal pelvis was excised carefully. The remaining tissue was dissected into 22 tissue samples per kidney, resulting in a total of 352 kidney samples from the 8 animals.

\section{Measurement of Radioactivity and Fluorescence}

For the determination of the radioactivity of the tissue samples, an automated $\gamma$-counter (Autogamma 5650, Canberra Packard, Frankfurt am Main, Germany) equipped with the software MIC III [6] was used. The program stores the dissection schemes and the sample weights and computes the blood flow values of the individual tissue samples per injection as well as the number of spheres per sample automatically. Before the measurement of radioactivity, each individual sample was placed into a pre-tarred scintillation vessel and weighed again. Radioactivity was determined by measuring the 
Table 2. Dissection of the heart

\begin{tabular}{|c|c|c|c|c|}
\hline Location & & Layers & $\begin{array}{l}\text { Samples/ } \\
\text { layer }\end{array}$ & $\begin{array}{l}\text { Samples/ } \\
\text { location }\end{array}$ \\
\hline Atria & & & & 8 \\
\hline Right ventricle & & 5 & 9 & 45 \\
\hline \multirow[t]{4}{*}{ Left ventricle } & & 6 & & \\
\hline & Sub-endo. & & 4 & 24 \\
\hline & Mid-myo. & & 4 & 24 \\
\hline & Sub-epi. & & 4 & 24 \\
\hline \multirow[t]{4}{*}{ Septum } & & 5 & & \\
\hline & Sub-endo. & & 2 & 10 \\
\hline & Mid-myo. & & 2 & 10 \\
\hline & Sub-epi. & & 2 & 10 \\
\hline
\end{tabular}

The hierarchy scheme for the dissection of the hearts provided 8 atrial and 45 right-ventricular tissue samples. Each specimen of the left ventricle and of the septum was sliced vertically into a sub-endo-, a mid-myo- and a sub-epicardial portion to allow the calculation of the sub-endo/sub-epicardial blood flow ratio. A total of 155 myocardial tissue samples was obtained from each heart using this hierarchy scheme.

counts per minute for $180 \mathrm{~s}$. The samples were then again removed from the scintillation tubes and brought into the filter unit of the SPU. The SPU-device has been designed and validated in vitro at the Institute for Surgical Research (Munich, Germany) and has proven to completely retract FM with a diameter of $15 \mu \mathrm{m}[2,5]$. The samples were processed automatically by a modified laboratory robot (Zymark, Idstein, Germany) [4]. The recovery of the FM from the tissue samples is performed by the digestion in $4 N$ aqueous $\mathrm{KOH}$ to which $0.2 \%$ of Tween 80 are added. The chemicals are pipetted automatically into the filter units of the SPU and are then layered with $1.5 \mathrm{ml}$ of isopropyl alcohol (100\%) [2]. The combination of the different liquids leads to the reduction of the surface tension of the $\mathrm{KOH}$. Thus, FM released from the tissue samples float in the centre of the surface of the leach and do not adhere to the filter's wall. Isopropyl alcohol shields the $\mathrm{KOH}$ from air thus avoiding crystallisation of the leach. The digestion of the samples takes place in the filter unit that is placed into a high grade steel container (beaker) (Perkin Elmer, Überlingen, Germany) for that purpose. The beaker (40 beakers/heater block) is closed with a lid and put into a heater block (Perkin Elmer) that maintains a constant temperature of $60^{\circ} \mathrm{C}$. The samples are digested within a period of 4-6 h, depending on their weight. At the end of the digestion, the content of the filters is sucked by means of a negative pressure of $400 \mathrm{hPa}$ through the polyamide wire mesh $(7 \mu \mathrm{m}$ mesh opening) which is fixed to the filter unit's lower end. The filter is then rinsed and washed with phosphate buffer and dried by centrifugation $(2,800 \mathrm{rpm})$. The filter unit is brought back into the SPU and the dyes are released from the FM by pipetting $2 \mathrm{ml}$ of Cellosolve-acetate (Sigma Aldrich, Deisenhofen, Germany) into the filter. The dye solution is collected in the sample tube by centrifugation. The sample tube is separated from the SPU and the fluorescence intensity of the dyes is measured online using an automated luminescence spectrometer (LS 50 B, Perkin Elmer). An overview of the sam- ple processing procedure is given in figure 1 . All the 12 steps of the procedure mentioned above are carried out by the robot [4]. A detailed description of the novel digestion method for processing tissue and blood samples as well as a description of the SPU and its validation has been given by Raab et al. [2].

The arterial reference samples were transferred from the collecting syringe into scintillation vessels. The syringe and the connected catheter were rinsed twice with saline which was mixed with $1 \%$ of Tween 80 (Merck, Hohenbrunn, Germany). This rinsing solution was brought into the scintillation vessels as well. After radioactivity of the blood samples had been measured, the blood of the reference samples $(40-60 \mathrm{ml})$ was transferred into three $50 \mathrm{ml}$ centrifuge tubes. $10 \mathrm{ml}$ of $6 \mathrm{~N} \mathrm{KOH}$ were added to each tube and the blood was digested in a water bath at a temperature of $60^{\circ} \mathrm{C}$ under soft motion within $6 \mathrm{~h}$. After vortexing and sonicating the centrifuge tubes for several minutes, the digested blood was filtered through the filter unit of the SPU by a negative pressure of $400 \mathrm{hPa}$. The tubes were then rinsed with phosphate buffer and vortexed and sonicated again. The buffer was filtered through the same filter as was the digested blood.

With the data of the measurement of radioactivity and fluorescence, the blood flow value for each sample and per injection was calculated according to the formula:

$$
\mathrm{RBF}=\mathrm{MS}_{\text {sample }} \times \mathrm{Vol}_{\text {pump }} \times \mathrm{MS}_{\mathrm{ref}^{-1}}
$$

where $\mathrm{MS}_{\mathrm{sample}}=$ number of microspheres in the tissue sample, $\mathrm{Vol}_{\text {pump }}=$ withdrawal-rate of the sampling pump, and $\mathrm{MS}_{\text {ref }}=$ number of microspheres in the reference blood sample.

Values based on the measurement of radioactivity were then compared with those calculated with data obtained from the fluorescence measurement.

In some of the experiments a period of several days (2-28) elapsed between the determination of radioactivity and fluorescence. During this period, the individual tissue samples lost weight due to drying. Blood flow values obtained with RM, respectively with FM, would consequently have been related to different sample weights, thereby influencing the comparability of the blood flow values. Therefore, the weight of the tissue samples determined prior to the measurement of radioactivity also served for the calculation of the blood flow values based on the FM technique.

\section{Statistical Analysis}

The data are presented as mean values $( \pm \mathrm{SD})$ and were analysed using the Student's $t$ test and the method of Bland and Altman [7].

\section{Exclusion of Blood Flow Values from the Analysis}

Blood flow values from tissue samples containing less than 400 microspheres were excluded from the analysis. In one experiment (No. 5), blood of 1 of the 6 arterial reference samples (fourth injection, injected microspheres: crimson and ${ }^{114} \mathrm{In}$ ) was spilled when the blood was transferred from the scintillation vessel into the digestion container. Together with the blood, microspheres of an undefined amount were lost. This happened after the determination of radioactivity and prior to the determination of fluorescence of this reference blood sample. Consequently, all blood flow values determined by the fourth injection of RM and FM, respectively, showed significant differences in this experiment. Therefore, all blood flow values determined by the fourth injection of experiment 5 were excluded from the analysis. 
Tissue Sample

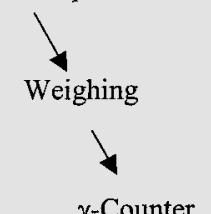

$\gamma$-Counter

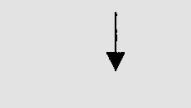

Measurement of

Radioactivity

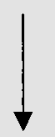

Blood flow values (1)

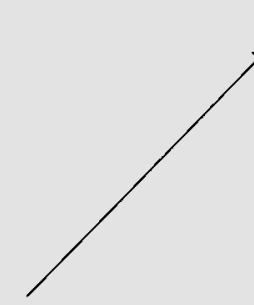

Tissue Sample

Sample Processing Unit

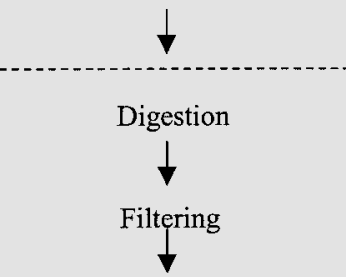

Rinsing and washing

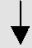

Centrifugation

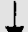

Dissolution of FM

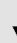

Dye-collection

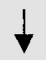

Measurement of

Fluorescence automatically by a robot. Finally the fluorescence intensity of the dyes was measured online by means of fluorescence spectrometry. The data of the radioactivity and fluorescence measurement were used to calculate the blood flow values for both methods which were compared then.

Fig. 1. Overview of the sample processing ty of the tissue samples was determined. The samples were then transferred into the sam-

\section{Results}

The surgical preparation took between 3 and $4 \mathrm{~h}$. The total duration of the individual experiments was between 5 and $7 \mathrm{~h}$. Before the first injection of microspheres took place, a period of $20 \mathrm{~min}$ was allowed for stabilisation of the animals following the surgical preparation. Between 12 and 18 min elapsed between 2 consecutive injections (table 2).

\section{Macrohemodynamics and Blood Chemistry}

None of the recorded macrohemodynamic parameters (heart rate, cardiac output, mean arterial and central venous pressure) changed significantly during the period of observation (approx. $90 \mathrm{~min}$ ) indicating that neither the surgical preparation nor the number of injected microspheres affected the macrohemodynamics. The hemodynamic and blood chemistry data are given in table 2 .
Only during the time of the injection of microspheres there was a slight increase of arterial blood pressure which, however, was reversible within $30 \mathrm{~s}$.

\section{Spleen Blood Flow}

The comparison of blood flow values of a total of 160 samples of the spleen that were determined with RM and FM showed excellent correlation $\left(r^{2}=0.97 \pm 0.03\right)$. The correlation coefficients of the individual experiments are given in table 3. Analysis of the data according to the method of Bland-Altman (fig. 2) revealed a mean percent difference of $5.4 \%( \pm 16.5 \%)$ between blood flow values obtained with RM and FM, respectively.

\section{Myocardial Blood Flow}

The comparison of blood flow values of a total of 1,240 tissue samples of the myocardium that were determined with RM and FM showed good correlation $\left(\mathrm{r}^{2}=0.95\right.$ \pm 0.03 ) (table 3). Overall myocardial blood flow mea- 
Fig. 2. Comparison of spleen blood flow values. A comprehensive Bland-Altman plot comparing spleen blood flow values obtained with RM respectively FM revealed a bias of $5.4 \%$ and a precision of $16.5 \%$. Solid line gives the mean difference between both methods, dashed lines represent the double standard deviation $(\mathrm{n}=913)$.

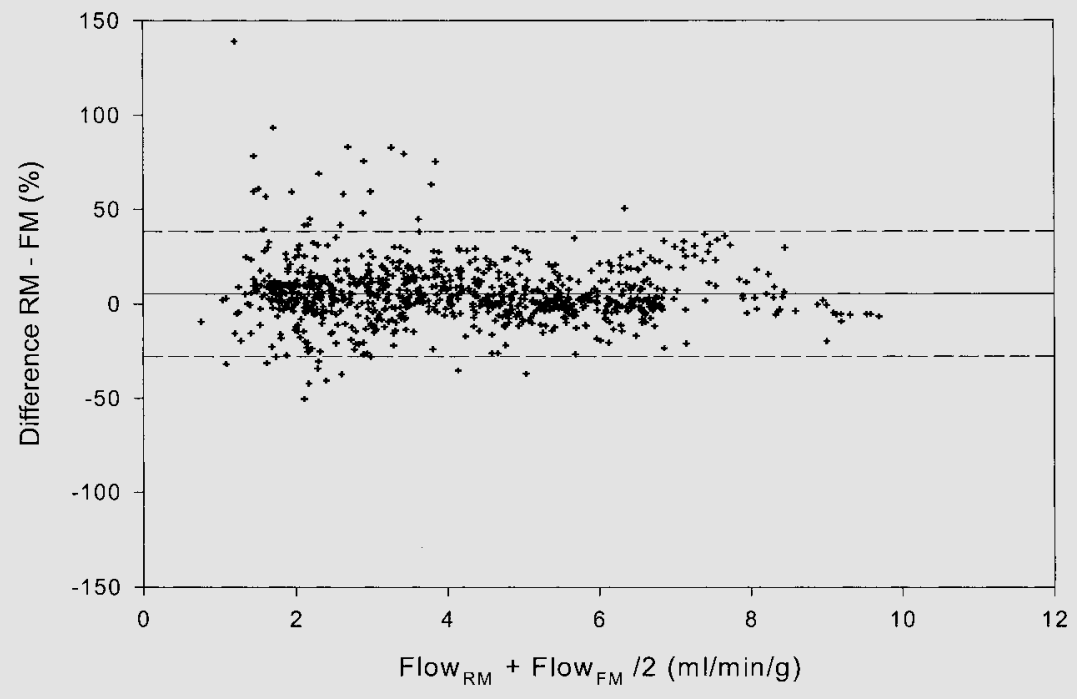

Table 4. Blood flow values of spleen, myocardium and kidney

Table 3. Correlation of both MS methods

\begin{tabular}{lllll}
\hline Experiment & $\mathrm{n}$ & Spleen & Myocardium & Kidney \\
\hline 1 & 6 & $0.96 \pm 0.03$ & $0.95 \pm 0.02$ & $0.96 \pm 0.03$ \\
2 & 6 & $0.96 \pm 0.04$ & $0.93 \pm 0.04$ & $0.98 \pm 0.01$ \\
3 & 6 & $0.95 \pm 0.03$ & $0.94 \pm 0.03$ & $0.93 \pm 0.07$ \\
4 & 6 & $0.96 \pm 0.02$ & $0.96 \pm 0.03$ & $0.99 \pm 0.01$ \\
5 & 5 & $0.97 \pm 0.02$ & $0.95 \pm 0.02$ & $0.99 \pm 0.01$ \\
6 & 6 & $0.96 \pm 0.04$ & $0.95 \pm 0.04$ & $0.99 \pm 0.00$ \\
7 & 6 & $0.96 \pm 0.04$ & $0.97 \pm 0.02$ & $0.98 \pm 0.02$ \\
8 & 6 & $0.95 \pm 0.03$ & $0.99 \pm 0.01$ & $0.97 \pm 0.02$ \\
\hline Mean & & $0.96 \pm 0.03$ & $0.95 \pm 0.03$ & $0.97 \pm 0.02$
\end{tabular}

The correlation coefficients (mean $\pm \mathrm{SD}$ ) of blood flow values of the individual experiments determined with radioactive and fluorescent microspheres show good agreement of the two methods throughout all individual experiments. $\mathrm{n}=$ Number of microsphere injections per experiment.

sured by $\mathrm{RM}$ was $1.54 \pm 0.99$ and $1.50 \pm 0.92 \mathrm{ml} / \mathrm{min} / \mathrm{g}$ when measured by FM. Bland-Altman [7] plots (fig. 3) revealed a mean percent difference of $-6.7 \pm 12.7 \%$ of both of the methods (table 4). The endo/epi blood flow ratio (table 5) of a total of 272 sub-endocardial respectively sub-epicardial tissue samples was $1.10 \pm 0.69$ when determined with FM and $1.09 \pm 0.53$ when determined with RM.

\begin{tabular}{|c|c|c|c|}
\hline & $\mathrm{n}$ & $\begin{array}{l}\mathrm{RM}(\mathrm{ml} / \mathrm{min} / \mathrm{g}) \\
\pm \mathrm{SD}\end{array}$ & $\begin{array}{l}\mathrm{FM}(\mathrm{ml} / \mathrm{min} / \mathrm{g}) \\
\pm \mathrm{SD}\end{array}$ \\
\hline Spleen & 913 & $3.98 \pm 1.94$ & $3.56 \pm 1.87$ \\
\hline Myocardium & 7,266 & $1.54 \pm 0.99$ & $1.50 \pm 0.92$ \\
\hline Kidney & 1,998 & $2.66 \pm 1.44$ & $2.84 \pm 1.49$ \\
\hline
\end{tabular}

The blood flow values determined by means of RM and FM are given as median $( \pm \mathrm{SD})$ of all experiments. The results show high agreement between both methods.

\section{Kidney Blood Flow Values}

The mean correlation coefficient of the blood flow values of the kidney calculated with data of the radioactivity and the fluorescence measurement was $0.97 \pm 0.02$ (table 3). The comparison of the values by Bland-Altman plots (fig. 4) showed a mean percent difference of $6.0 \%$ $( \pm 9.9 \%)($ table 4$)$.

Kidney blood flow values determined by means of RM yielded $2.61 \mathrm{ml} / \mathrm{min} / \mathrm{g}( \pm 0.61)$ for the left, respectively $2.38 \mathrm{ml} / \mathrm{min} / \mathrm{g}( \pm 0.62)$ for the right kidneys. In comparison to these values, blood flow values measured with FM $(2.58 \pm 0.58 \mathrm{ml} / \mathrm{min} / \mathrm{g}$, left kidneys and $2.43 \pm 0.68 \mathrm{ml} /$ $\mathrm{min} / \mathrm{g}$, right kidneys) were almost identical. 
Fig. 3. Comparison of blood flow values of the myocardium. A comprehensive BlandAltman plot comparing myocardial blood flow values obtained with RM and FM revealed a bias of $-6.7 \%$ and a precision of $12.7 \%$. Solid line gives the mean difference between both methods, dashed lines represent the double standard deviation $(\mathrm{n}=$ $7,265)$.

Table 5. Sub-endo- and sub-epicardial blood flow values

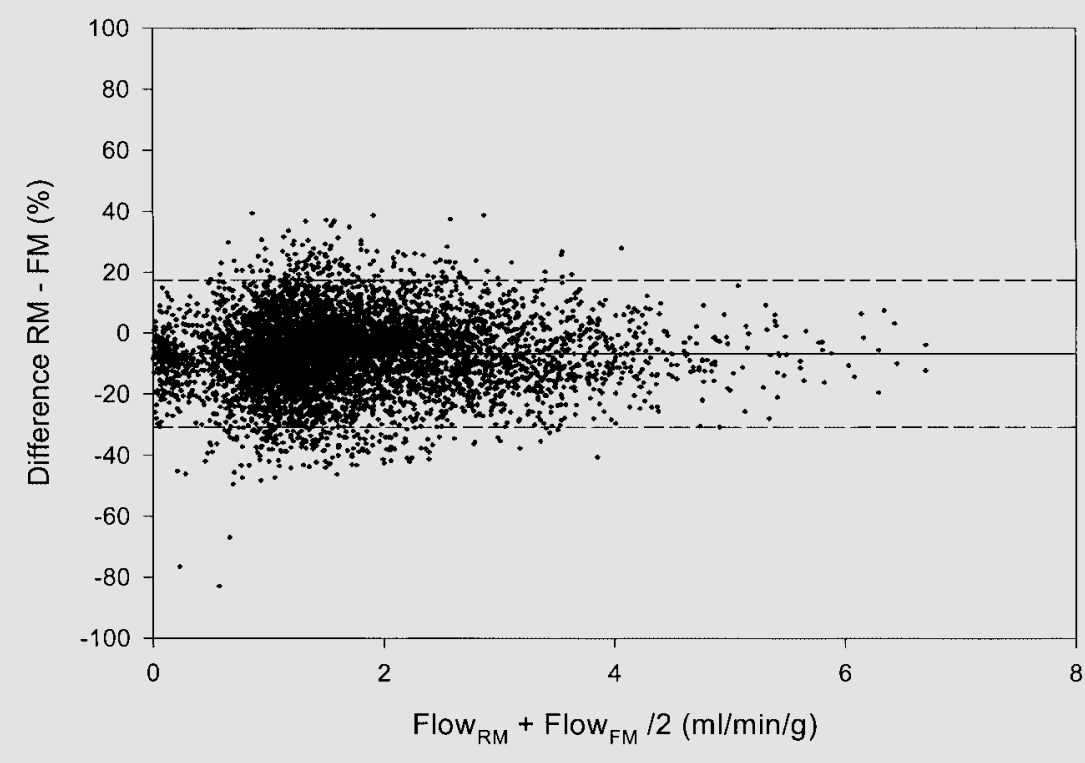

\begin{tabular}{|c|c|c|c|c|c|c|}
\hline \multirow[t]{2}{*}{$\begin{array}{l}\text { Injection } \\
\text { No. }\end{array}$} & \multicolumn{2}{|c|}{$\begin{array}{l}\mathrm{RMBF}, \mathrm{ml} / \mathrm{min} / \mathrm{g} \\
\text { sub-endocardial }\end{array}$} & \multicolumn{2}{|c|}{$\begin{array}{l}\mathrm{RMBF}, \mathrm{ml} / \mathrm{min} / \mathrm{g} \\
\text { sub-epicardial }\end{array}$} & \multicolumn{2}{|l|}{$\begin{array}{l}\text { Endo/Epi } \\
\text { ratio }\end{array}$} \\
\hline & FM & $\mathrm{RM}$ & FM & RM & FM & $\mathrm{RM}$ \\
\hline 1 & $1.50 \pm 0.86$ & $1.31 \pm 1.07$ & $1.36 \pm 0.83$ & $1.21 \pm 0.52$ & $1.08 \pm 0.61$ & $1.11 \pm 0.70$ \\
\hline 2 & $1.81 \pm 1.08$ & $1.49 \pm 0.70$ & $1.53 \pm 1.17$ & $1.42 \pm 0.70$ & $1.08 \pm 0.53$ & $1.08 \pm 0.48$ \\
\hline 3 & $1.65 \pm 0.74$ & $1.75 \pm 0.59$ & $1.27 \pm 1.15$ & $1.68 \pm 0.67$ & $1.16 \pm 0.90$ & $1.09 \pm 0.49$ \\
\hline 4 & $2.20 \pm 1.13$ & $2.29 \pm 0.94$ & $1.83 \pm 1.17$ & $2.28 \pm 0.81$ & $1.09 \pm 0.53$ & $1.03 \pm 0.54$ \\
\hline 5 & $1.85 \pm 1.53$ & $1.60 \pm 1.30$ & $1.75 \pm 1.47$ & $1.54 \pm 1.12$ & $1.10 \pm 0.49$ & $1.08 \pm 0.46$ \\
\hline 6 & $1.95 \pm 1.56$ & $1.73 \pm 1.33$ & $1.61 \pm 1.76$ & $1.50 \pm 1.15$ & $1.14 \pm 0.56$ & $1.13 \pm 0.49$ \\
\hline Mean of al & $1.83 \pm 0.24$ & $1.70 \pm 0.33$ & $1.56 \pm 0.24$ & $1.61 \pm 0.35$ & $1.10 \pm 0.69$ & $1.09 \pm 0.53$ \\
\hline
\end{tabular}

The sub-endocardial respectively sub-epicardial blood flow (RMBF) values of the left ventricle determined by means of RM and FM at each time point of injection are given as median ( \pm SD). The results of a total of 272 tissue samples from all experiments of either location show good agreement between the two microsphere methods. The sub-endocardial to sub-epicardial blood flow ratios determined by FM are almost identical with the ratios obtained with RM.

\section{Discussion}

The results of the hemodynamic monitoring indicate that there was no influence on the blood flow values by the number of microspheres injected, even though the total number of spheres given in each experiment amounted up to $4.8 \times 10^{7}$. This finding is in agreement with data from other authors $[8,9]$.

The absolute blood flow values of kidney and spleen determined in the present study by means of FM and RM, respectively, are in the same range as reported in other publications [10-12]. In addition, the myocardial blood 
Fig. 4. Comparison of kidney blood flow values. A comprehensive Bland-Altman plot comparing renal blood flow values obtained with RM respectively FM revealed a bias of $-6.0 \%$ and a precision of $9.9 \%$. Solid line gives the mean difference between both methods, dashed lines represent the double standard deviation $(\mathrm{n}=1,998)$.

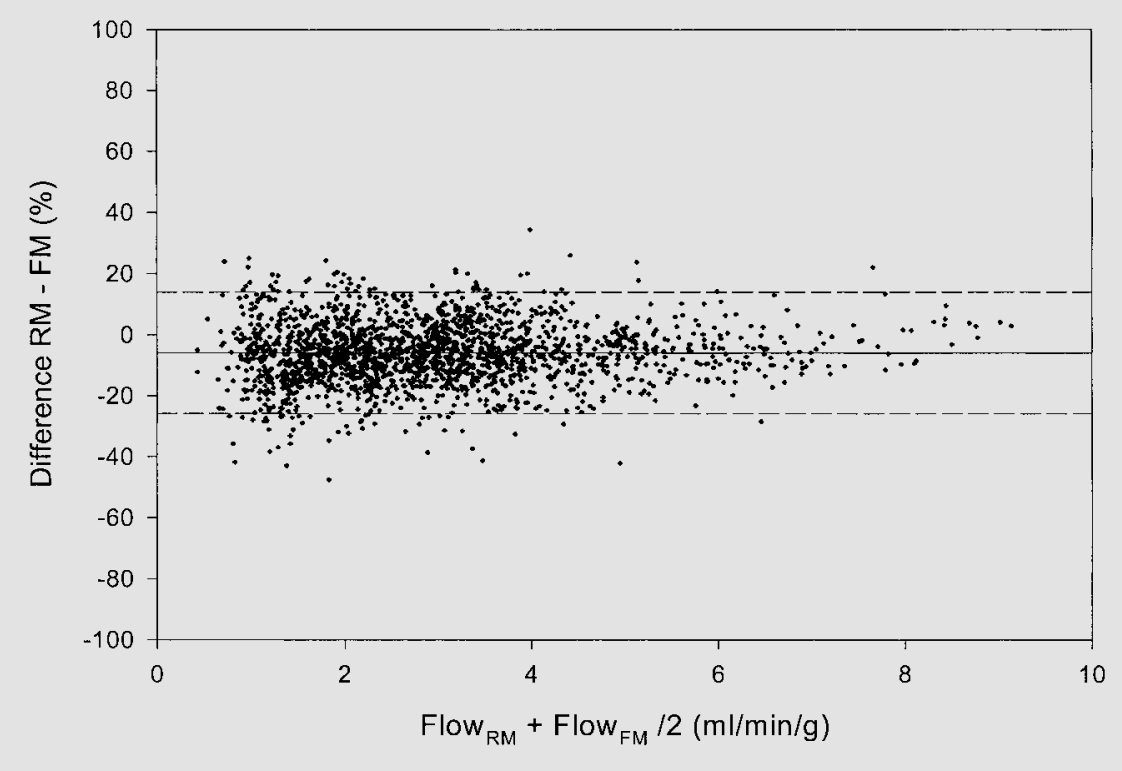

flow values as well as the ratio of sub-endocardial to subepicardial blood flow were found in good agreement with the data obtained in previous studies [12-17].

Although the reference blood samples were heparinised, coagula formed in the blood of most of the samples during the time between determination of radioactivity and recovery of the FM from these samples. Therefore, digestion of the reference blood samples was necessary to extract the FM from the blood. As a consequence the blood had to be transferred several times from one into another container. This transfer might have led to a loss of FM from the reference blood samples as indicated by the significant difference for the colour crimson in experiment 5 . Therefore, the blood flow values of this measurement were excluded from the analysis. In addition, the potential loss of FM from the reference blood samples may also explain the fact that some colours yield blood flow values that are closer to the values determined with radioactive microspheres than others. However, if the FM can be recovered from the blood reference samples within $24 \mathrm{~h}$, direct filtration of the blood is possible using the filter unit of the SPU. As we have recently shown, the addition of CPDA-1-anticoagulation-stabilizer (26.3 g sodium citrate dihydrate, $3.27 \mathrm{~g}$ citric acid monohydrate, $31.9 \mathrm{~g}$ glucose monohydrate, $2.51 \mathrm{~g}$ sodium dihydrogen phosphate dihydrate and $0.275 \mathrm{~g}$ adenine dissolved in $1,000 \mathrm{ml}$ water for injection; $2 \mathrm{ml}$ stabilizer for $10 \mathrm{ml}$ blood) to the syringe in which the arterial reference is collected allows for the first time direct filtration of the blood, thus excluding the loss of FM from the arterial reference [2].

The comparison of blood flow values that were calculated with the data from the fluorescence and the radioactivity measurement showed good correspondence and high reproducibility, indicating that the RBF values determined with FM are valid and reliable. The correlation coefficients and the corresponding standard deviations of the blood flow values of the different experiments were found in the range reported by other researchers $[1,3]$.

\section{Conclusion}

Measurement of RBF can be performed reliably with both, FM and RM. The complete automation of the preparation of tissue samples for the measurement of fluorescence reduces the time that is needed for sample processing to a minimum. As the robot is performing the procedure with more constancy and a higher precision than manual sample processing, the FM method can be comfortably standardized. 


\section{References}

1 Glenny RW, Bernard S, Brinkley M: Validation of fluorescent-labeled microspheres for measurement of regional organ perfusion. J Appl Physiol 1993;74:2585-2597.

2 Raab S, Thein E, Harris AG, Messmer K: A novel filtration device for recovering fluorescent microspheres from tissue samples. Am J Physiol 1999;276:H1801-H1806.

3 Van Oosterhout HM, Willigers RS, Reneman MFM, Prinzen FW: Fluorescent microspheres to measure organ perfusion: Validation of a simplified sample processing technique. Am J Physiol 1995;269:H725-H733.

4 Thein E, Raab S, Harris AG, Messmer K: Automation of the use of fluorescent microspheres for the determination of regional blood flow. Comp Meth Prog Biomed 2000;61:1121.

5 Glenny R: Perkin Elmer Filtration Units (September 1997). http://www.fmrc.pulmcc.washington.edu

6 Gross W, Schosser R, Messmer K: MIC-III - an integrated software package to support the radioactive microsphere technique. Comput Methods Prog Biomed 1990;33:65-85.
7 Bland JM, Altman DG: Statistical analyses for assessing agreement between two methods of clinical measurements. Lancet 1986;8476: 307-310.

8 Kaihara S, Van Heerden PD, Migita T, Wagner $\mathrm{HN}$ : Measurement of distribution of cardiac output. J Appl Physiol 1968;25:696-700.

9 Wagner HN, Rhodes BA, Sasaki Y, Ryan JP: Studies of the circulation with radioactive microspheres. Invest Radiol 1969;4:374-386.

10 Stonestreet BS, Ocampo SS, Oh W: Reductions in cardiac output in hypoxic young pigs. Systemic and regional perfusion and oxygen metabolism. J Appl Physiol 1998;85:874-882.

11 Maharajh GS, Pascoe EA, Halliday WC, Grocott HP, Thiessen DB, Girling LG, Cheang MS, Mutch WA: Neurological outcome in a porcine model of descending thoracic aortic surgery. Left atrial-femoral artery bypass versus clamp/repair. Stroke 1996;27:2095-2100; discussion 2101.

12 Tranquilli WJ, Manohar M, Parks CM, Thurmon JC, Theodorakis MC, Benson GJ: Systemic and regional blood flow distribution in unanesthetized swine and swine anesthetized with halothane and nitrous oxide, halothane, or enflurane. Anesthesiology 1982;56:369-379.
13 Habler O, Kleen M, Pape A, Meisner F, Kemming G, Messmer K: Diaspirin-crosslinked hemoglobin reduces mortality of severe hemorrhagic shock in pigs with critical coronary stenosis. Crit Care Med 2000;28:1889-1898.

14 Lurie KG, Coffeen P, Shultz J, McKnite S, Detloff B, Mulligan K: Improving active compression-decompression cardiopulmonary resuscitation with an inspiratory impedance valve. Circulation 1995;91:1629-1632.

15 Pantely GA, Malone SA, Rhen WS, Anselone CG, Arai A, Bristow J, Bristow JD: Regeneration of myocardial phosphocreatine in pigs despite continued moderate ischemia. Circ Res 1990;67:1481-1493.

16 Massie BM, Schaefer S, Garcia J, McKirnan MD, Schwartz GG, Wisneski JA, Weiner MW, White FC: Myocardial high-energy phosphate and substrate metabolism in swine with moderate left ventricular hypertrophy. Circulation 1995;91:1814-1823.

17 Massie BM, Schwartz GG, Garcia J, Wisnesk JA, Weiner MW, Owens T: Myocardial metabolism during increased work states in the porcine left ventricle in vivo. Circ Res 1994;74: 64-73. 